\title{
Uma escuta sensivel: a teatralidade contemporânea na performance O Semeador de Poesias
}

GONÇALVES, Luiz Davi Vieira ${ }^{1}$

Resumo

O presente artigo visa a apresentar uma investigação desenvolvida dentro do Corpo Cênico: Núcleo de Pesquisa e Experimentações Artísticas, do Centro de Educação Profissional em Artes Basileu França, em Goiânia-GO (CEPABF/GO), intitulada O Semeador de Poesias. A obra surgiu a partir da experiência cênica com o arquétipo da Mandala, com vivências em espaços públicos e reflexões sobre o corpo do ator e suas poéticas.

Palavras-chave: performance; teatralidade; espaço.

\section{Abstract}

This article presents an investigation developed within the Scenic Body - Center for Research and Trials Theater, the Center for Professional Education in Arts Basileu France - CEPABF / GO titled "The Sower of Poetry." The work emerged from the scenic experience with the archetype of the Mandala with experiences in public spaces and reflections on the actor's body and their poetics.

Keywords: performance; theatricality; space.
Professor Efetivo na Universidade do Estado do Amazonas. Mestre em História pela Pontifícia Universidade Católica de Goiás, graduado em Artes Cênicas pela Universidade Federal de Goiás, performer, pesquisador e coordenador do Corpo Cênico: Núcleo de Pesquisa e Experimentações Artísticas, entre o período de 2009 a 2012. Responsável pela Direção do espetáculo O Semeador de Poesias. 
O presente artigo é parte da pesquisa desenvolvida no Corpo Cênico: Núcleo de Pesquisas e Experimentações Artísticas, que resultou na criação do espetáculo O Semeador de Poesias. O objetivo desse texto é compartilhar com os pesquisadores, artistas e comunidade em geral o caminho traçado para a construção desta obra teatral.

O grupo foi constituído pelo desejo dos professores e alunos da área de teatro do Centro de Educação Profissional em Artes Basileu França (CEPABF), Escola de Arte Veiga Valle, da cidade de Goiânia-GO, de proporcionar ao aluno uma investigação no campo das artes e consolidar um grupo que representasse os trabalhos desenvolvidos na área de teatro dentro da escola.

O Corpo Cênico estreou em 2010, no Desaguar - Mostra Teatral do CEPABF, com a instalação performática O Semeador de Poesias, trazendo para o Teatro Escola Basileu França novas possibilidades de ocupações cênicas e seus espaços. O projeto de montagem teve o papel de fomentar a poesia e os conceitos de performance tanto na escola quanto nas cidades por onde passou. A escolha das poesias de Sebastião Nei Rodrigues, da cidade histórica de Pirenópolis-GO, deu-se na importância de valorizar autores de nosso estado, refletir sobre nossas raízes e nossos desejos de romper com as formatações convencionais do teatro, buscando signos teatrais que pudessem refletir acerca da nossa cultura e as teatralidades contemporâneas.

O projeto nasceu do processo dos alunos a partir do diálogo com os princípios contemporâneos das artes plásticas, do teatro e da literatura, sob a orientação dos professores ${ }^{2}$ da referida instituição, propondo uma ressignificação dos espaços públicos e/ou do espaço cênico, bem como a desconstrução da linguagem teatral e criando, assim, uma teatralidade ${ }^{3}$ genuína no processo de investigação do grupo.

\section{Uma escuta sensivel}

A obra surgiu, para o grupo, a partir da experiência cênica com o arquétipo da Mandala ${ }^{4}$, com vivências em espaços públicos, estudo das poesias e do imaginário do autor. Antes desse processo do Corpo Cênico, foi desenvolvido um elo criativo de experiências cênicas entre o autor da obra, o diretor e a colaborada Dra. Julia Pascali, responsável pela inspiração de todo o processo, no qual as sensibilidades,
2. Adriana Magre de Brito, Leonardo Flôres, Thiago Santana, Michel Mauch, Renata Mello e demais professores da área.

3. Segundo Josette Féral, (2009, p 108) a Teatralidade produz eventos espetaculares para o espectador, que estabelece uma relação que difere do cotidiano. É um ato de representação, a construção de uma ficção Como tal, a teatralidade é a imbricação de ficção e representação em um espaço de "outro" em que o observador e o observado são trazidos face a face.

4. Segundo Maura Baiocchi e Wolfgang Panner (2007, p. 141), é um veículo para tonificar, harmonizar e expandir a pentamusculatura com prazer e lucidez. Envolve exercícios de respiração, alongamento, flexibilidade, intratensões, visualização, improvisação e as práticas do olho interior e dos sons do corpo. 
as imaginações criativas e as ligações artísticas foram compartilhadas no período de uma década até o surgimento do referido trabalho.

Sebastião Nei Rodrigues nasceu em 21 de setembro de 1975, em Pirenópolis, cidade do Estado de Goiás, Brasil. Filho de João Pereira Rodrigues e Antônia Ribeiro Rodrigues, que perceberam desde o início as inquietações do filho com seus olhares e formas diferenciadas de perceber e se comunicar com o mundo por meio de seus poemas. Ainda criança, sofreu incompreensões sobre suas experiências e buscou, na religião, respostas, que não foram sanadas. Tornou-se cantor sacro após essa conexão com o sagrado. Logo, passou a conduzir sua sensibilidade à técnica da escultura. Esculpia sempre bustos de mulheres. Após conhecer a professora e performer Júlia Pascalli, iniciou seu caminho na escrita, o que lhe permitiu inspirar-se em formas mais poéticas. Mesmo não possuindo nenhuma formação superior, apenas o segundo grau completo, desenvolveu sua primeira obra dentro das características do Romantismo do século XIX, aproximando-se de Álvares de Azevedo5. O caminho como escritor foi constituído em trilhos muito árduos e difíceis. Nei queimava todos os seus poemas até conseguir compor sua única obra publicada: O Semeador de Poesias.

O autor desenvolve, até hoje, processos em que ele materializa suas sensibilidades diante do mundo. Como semear? Qual de vós é a semente? Quantos anos eu terei nestas sementes? O que fará de mim um ser? Quantos virão depois de mim? Personagens de um poeta existencialista são personificadas em busca da definição do amor e de outros sentimentos. Com essas inspirações e questionamentos, o Corpo Cênico iniciou suas pesquisas relacionando seu processo teatral ao mundo sensível do autor pirenopolino.

Teatralidades: um encontro entre teatro, artes plásticas e poesias

Pesquisas foram desenvolvidas com o objetivo de sensibilizar a relação do teatro com a dança e as artes plásticas e outras linguagens que fossem constituídas por meio de experimentações; e suas interfaces históricas, por meio do imaginário a que a poesia nos conduz, tendo como base um processo de produção e mecanismos do próprio grupo, como treinamentos corporais; estudo do movimento e do corpo no espaço; estudo da composição orgânica corpo-mente; investigações cênicas; improvisações; criações e pesquisas teóricas.

\author{
5. Álvares de Azevedo \\ (1831-1852) foi poeta, \\ escritor e contista \\ da segunda geração \\ romântica brasileira. \\ Suas poesias retratam \\ o seu mundo interior. \\ É conhecido por alguns \\ pesquisadores como "o \\ poeta da dúvida”.
}


Por sua vez, a concepção cênica das últimas décadas pôde se multiplicar em várias vozes e, com isso, dissolver sua autoria entre os vários profissionais da equipe. Poderíamos exemplificar essa forma de trabalho com uma tendência teatral contemporânea calcada na horizontalidade das relações criativas: o processo colaborativo. Neste, a partir da escolha de um tema, o grupo propõe um material de estudo que deve ser acessível a todos os membros. Pesquisam-se leituras, imagens, sons, figurinos e adereços, em um exercício de complementaridade.

Por conseguinte, os elementos cênicos foram sendo compostos a partir das indagações e inquietudes do autor e do elenco, possibilitando ao público afetar-se ${ }^{6}$ em seus diferentes níveis de percepção e apreciação estética.

Desse modo, foi possível reproduzir, nas diversas salas de apresentações, um pouco do imaginário interiorano de Goiás. As sensações mais inquietantes dos poemas de Sebastião Nei são materializadas pelos corpos que ocupam espaços não convencionais, atribuindo-se, assim, um novo olhar ao que parecia habitual.

A instalação performática O Semeador de Poesias sugeriu possibilidades linguísticas e comunicativas que partiam do trabalho do ator, da estética elaborada no espaço ocupado, da relação entre eles e a recepção desse público, oriundo de diversas culturas - proporcionando, assim, um olhar diferente a cada apresentação.

No tocante à concepção, é impossível atribuir uma linguagem pura à performance ${ }^{7}$. Ela é híbrida ou consubstanciada; dá-se por releitura de propostas e justaposição com outras artes. Com tal efeito, este trabalho de construção (ou desconstrução) está integrado aos elementos utilizados no espetáculo, que são os mais diversos possíveis: danças, vídeos, folhas secas, fogo e água, mídias etc. Ademais, o processo de criação, diversamente do teatro dramático, inicia-se pela forma, e não pelo conteúdo - ou seja, parte-se do significante para se chegar ao significado.

A imagem cria o sentido pela materialidade visual na ressignificação do espaço e pela apropriação do mesmo, gerando, assim, o efeito próprio para a recepção estética e, consequentemente, acusando uma escuta sensível ${ }^{8}$ nos espectadores, que permite transpor as esferas da dor, amor e saudade das páginas surradas de um poeta desconhecido do interior do Brasil para uma dimensão poética, além das fronteiras culturais.
6. O conceito de afetar utilizado neste processo é definido a partir da abordagem de Spinoza apresentado por Souza: "O quê pode um corpo?”, pergunta Spinoza (1989). A resposta do filósofo é simples e direta: "(...) afetar e ser afetado. Esta é a potência própria a um corpo vivo. Ora, qualquer vivo afeta e é afetado, e isto define o modo como age, reage, sente e "lida" com seus processos vitais" (Souza, 2005, p. 36).

7. Tema complicado para uma definição pura; entretanto, sem dúvida, Josette Féral é uma das maiores estudiosas acerca do tema. É importante ressaltar as palavras da Professora da Universidade de São Paulo, Dra. Silvia Fernandes, sobre o assunto definido por Féral: a performance define-se como uma força dinâmica cujo principal objetivo é desfazer as competências do teatro, que atende a inscrever o palco numa semiologia específica e normativa. Caracterizando por estrutura narrativa e representacional, o teatro maneja códigos com a finalidade de realizar determinada inscrição simbólica do assunto, ao contrário da performance, que expressa fluxos de desejo e tem por função desconstruir o que o primeiro formatou.

8. O conceito de escuta, aqui abordado, é definido por José Martins: "A escuta cultiva a qualidade da observação, convocando-se os sentidos - visão, audição, olfato, paladar e tato, no sentido de si, do outro e do espaço" (2005, p. 11). 
No período de novembro de 2010 até janeiro de 2012, tempo em que o espetáculo esteve em funcionamento, o grupo apresentou-se em diversos eventos, como no Festival Internacional de Poesias de Pirenópolis (FLIPIRI), como convidado para homenagear o poeta Sebastião Nei Rodrigues. O grupo foi selecionado para o Festival Nacional de Teatro de Goiânia e a Mostra Curta Mix; nesta última, o trabalho foi premiado em primeiro lugar, recebendo um convite para participar do Circuito da Cena, promovido pelo Galpão Cine Horto, em Goiânia, de 23 a 25 de setembro de 2011. O Semeador de Poesias também saiu das fronteiras brasileiras para representar o Estado de Goiás no $23^{\circ}$ Festival Internacional de Teatro Comunitario, na cidade de Santiago, Chile.

A participação neste festival possibilitou a reflexão sobre as manifestações sociopolíticas e culturais daquela comunidade, por se tratar de um teatro comunitário, e levou a um conhecimento transformador a respeito das ações artísticas daquele grupo, ainda marcado por resquícios de uma ditadura, apresentando, em suas manifestações teatrais, um desejo de libertação. Estabeleceu-se, de maneira embrionária no Popul Teatro ${ }^{9}$, uma atitude reflexiva acerca da abordagem estética naquele contexto artístico, que foi além das questões políticas do país. Com isso, proporcionou-se um entrecruzamento de conceitos e experiências acerca das modalidades de resistência, estado de risco e fundamentos da teatralidade, que percorrem a linguagem da performance em seus diferentes contextos, bem como os ideais do teatro comunitário e político nos anos de ditadura da América Latina, que teve como representante Augusto $\mathrm{Boal}^{10}$, grande influência no trabalho teatral desse evento. Logo, foi criada uma grande atmosfera mágica, que alterou a memória do ENTEPOLA (Chile) e dos atores do Corpo Cênico.

O percurso de viagem, com suas inúmeras circunstâncias, ofereceu as primeiras transformações no processo de imersão cultural do grupo, pois, tão importante quanto representar uma instituição, estado e país, é o contato com a cultura do destino visitado. No caso específico do espetáculo que foi apresentado, as sensações, descobertas culturais e a apropriação de imagens e do imaginário de outro país alteraram os aspectos sensíveis dos atores e pessoas envolvidas, de forma a refletir no resultado do trabalho. Nesse sentido, sair do centro-oeste brasileiro, passar pelo sudeste, cruzar a Argentina e entrar no Chile, cercados pelo cenário das Cordilheiras dos Andes, fez de o Semeador de Poesias um novo espetáculo.
9. Momento de discussão e debates do Festival entre os participantes.

10. Augusto Pinto Boal (16/03/1931 02/05/2009), diretor, dramaturgo, ensaísta e criador do Teatro do Oprimido. 


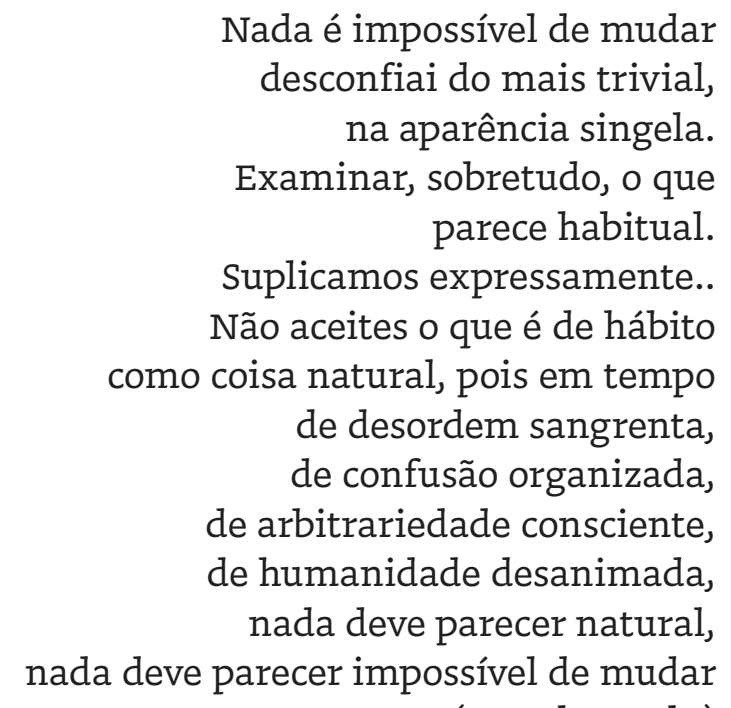

(Bertolt Brecht)

O teatro se reinventa a cada dia, com múltiplas faces, e se coloca a todo instante em interface com a dança, o cinema, as artes plásticas e tantas outras manifestações artísticas. Por isso, é difícil tarefa decifrá-lo. Todavia, a teatralidade aparece como um dos caminhos para nos conduzir ao entendimento do teatro contemporâneo, ou, pelo menos, a uma forte fundamentação reflexiva acerca do hibridismo teatral. Para tal efeito, Josette Féral afirma que as tentativas de conceituar teatralidade estão ligadas às recentes preocupações com a teoria do teatro (2002, p. 94). Contudo, os caminhos são pantanosos e, segundo Féral, "(...) teatralidade é tanto pobremente definida quanto etimologicamente nuclear»11 (2002, p. 95, tradução livre).

A forma como um espetáculo ou evento se estrutura na performance é extremamente diversa do teatro dramático. Acompanha-se uma mudança total de mentalidade do valor da cena para a comunicação humana. Consideramos o performer um ator total porque, autor-ator, é fruto de um adestramento amplo, o que nem sempre ocorre no treinamento do ator e do dançarino tradicionais, entendidos como aqueles que apenas executam o que é solicitado pelo diretor ou coreógrafo. O performer é geralmente criador e intérprete de sua obra. "Autor-ator-dançarino", o performer exige o princípio da dramaturgia no sentido de "fato cênico" comunicado ao espectador. De acordo com Renato Cohen (2009), existe uma estreita passagem entre a representação e a atuação, "menos deliberada, com espaço para o improviso, para a espontaneidade, que caminha a live art, com as expressões happening e performance" (Cohen, 2009, p. 97). Além disso, na perfor-
11. No original:

"(...) theatricality is both poorly defined and etymologically nuclear"

(FÉRAL, 2002, p. 95). 
mance há uma acentuação muito maior do instante presente, do momento da ação, o que enfatiza o aspecto da "atuação".

Talvez a marca mais forte que vá caracterizar, na atuação, o performer como alguém distinto do ator-intérprete é essa capacidade de condução do espetáculo-ritual, valorizando a live art, a arte que está acontecendo ao vivo, no instante presente (COHEN, 2009, p. 109; grifo do autor).

Em distinção ao ator dramático, o performer não tem necessariamente um personagem para mostrar, mas terá que "se mostrar". Segundo Cohen (2009), o trabalho de criação e preparação do performer aponta basicamente para dois caminhos: o desenvolvimento de suas habilidades psicofísicas e a busca de seu desenvolvimento pessoal.

A teatralidade pode acontecer sob várias perspectivas. É um processo de olhar ou ser olhado (FÉRAL, 2002). Para tal efeito, percebemos o quanto a função de quem está diante da obra, ou seja, o espectador, faz-se necessária. Este espaço também pode ser além dos muros de um teatro enquanto edifício, pois a teatralidade não necessita de regras acerca de sua espacialidade. Entretanto, isso nos conduz a uma reflexão: será necessária a presença de um ator para ocorrer uma teatralização? Para ter uma teatralidade?

Ainda seguindo o pensamento da ensaista Josette Féral (2002), "O ator é, simultaneamente, produtor da teatralidade e o canal através do qual ela passa ${ }^{12 "}$ (FÉRAL, 2002, tradução livre). Percebe-se que o ator codifica os sinais dentro das estruturas simbólicas do palco, da instalação de qualquer lugar onde aconteça uma representação artística. Ele pode conduzir o espectador ao significado, oferecendo-lhe um caminho reflexivo e ativo diante do imaginário da obra. Todavia, está sempre ameaçado por uma falta de adequação com os signos que compõem a cena, pois nem sempre o planejado ocorre como se espera. O ator pode dialogar com tudo o que está ao seu redor: espaço, tempo, história, cenário, música, iluminação e figurinos. Traz a teatralidade ao palco (FÉRAL, 2002). É importante resaltar que o ator pode fazer isso tudo por ser um condutor para os signos de uma representação, mas nem sempre isso acontece. Sua ação é estabelecida por meio de regras derivadas de um conjunto de elementos, que podem corresponder a pensamentos de outros profissionais. Ou seja, a teatralidade não surge por uma forma passiva, como pontua Féral:

Teatralidade não surge de forma passiva a partir de um conjunto de objetos teatrais, cujas propriedades se poderia enumerar num relance, mas como parte de um processo dinâmico pertencendo a ambos o agente e o espectador, que toma posse da ação, ela observa ${ }^{13}$ (FÉRAL, 2002, p. 103, tradução livre).
12. No original: "The actor is simultaneously the producer of theatricality and the channel through which it passes" (FÉRAL, 2002).

13. No original: "Theatricality does not emerge passively from an ensemble of theatrical objects whose properties one could enumerate at a glance, but as part of a dynamic process belonging to both the actor and the spectator, who takes possession of the action he watches" (FÉRAL, 2002) 
Torna-se importante ressaltar, diante dessa reflexão, que o ator é elemento importante para um encontro com a teatralidade, mas sua ausência não impossibilita a existência de signos teatrais, pois o processo ligado às condições da produção teatral também são elementos que podem teatralizar uma encenação.

\section{Considerações finais}

Pelo estudo aqui realizado, percebemos que não existe uma poética estabelecida, ou um único ponto de partida para o nascimento da encenação teatral contemporânea. Ela poderá surgir das leituras de mesa de um texto dramático, assim como de vários outros estímulos criativos, tais como imagens, sons, jogos, improvisações ou ações propostas. Como reflexo dessas metamorfoses, a ideia de teatro também se transforma a cada encenação, a cada público, a cada leitura de mundo que um encenador pretende fazer. Não obstante às suas frequentes reinvenções, o teatro será assegurado pelo insubstituível diálogo entre atores e público. Além disso, um dos caminhos para se refletir o fazer teatral é entender o contexto, os signos, o que envolve e constitui uma cena.

Portanto, estudar a teatralidade tendo como foco as poesias de Sebastião Nei, o processo de pesquisa dos atores e os espaços em que passamos não se configuram em apenas desenvolver uma pesquisa sobre teatro, artes plásticas ou sobre técnicas propicias para se chegar a algum lugar. Pesquisar a teatralidade e suas interfaces é acreditar na transformação que a arte pode provocar no ser humano, é acreditar que a arte teatral pode chegar a lugares que ninguém imagina, como por exemplo: o olhar de um homem diante de uma obra de arte. Sendo assim, esse trabalho é apenas uma provocação provisória. 


\section{REFERÊNCIAS BIBLIOGRÁFICAS:}

Baiocchi, Maura; PANNEK, Wolfgang. Taanteatro: teatro coreográfico de tensões. Rio de Janeiro: Azougue Editorial, 2007.

BRILHANTE, Maria João. (Orgs.). Texto e Imagem: estudos de teatro. Rio de Janeiro: JLetras, 2009. pp. 9-28.

Perspectiva, 2010. Teatralidades Contemporâneas. São Paulo:

CAMARGO, Robson Corrêa de; REINATO, Eduardo José; CAPEL, Heloisa Selma Fernandes (Orgs.). Performances Culturais. São Paulo: Hucitec, 2011.

COHEN, Renato. Performance como linguagem: criação de um tempo-espaço de experimentação. 2 ed. São Paulo: Perspectiva, 2009.

Work in Progress na Cena Contemporânea.

São Paulo: Perspectiva, 2006.

CORNAGO, Óscar. Qué es la teatralidad? Paradigmas estéticos de la Modernidad. Telondefondo, $\mathrm{n}^{\circ} 1$, agosto de 2005.

Teatralidade e Ética. Próximo Ato: São

Paulo: Itaú Cultural, 2008.

FÉRAL, Josette. Theatricality: the specificity of theatrical language. Substance Issue, 98/99, v. 31, n. 2 e 3, 2002.

. Théâtralité, escriture et mise em scène. Québec:

Hurtubise, 1985.

Gonçalves, Luiz Davi Vieira. A Teatralidade na Obra de Siron Franco: Uma relação entre História, Teatro e Artes Plásticas (1988 a 1999). Dissertação (Mestrado em História). Pontifícia Universidade Católica de Goiás, 2012.

FERNANDES, Silvia. Teatralidades Contemporâneas. In: WERNERCK, Maria Helena; 